\title{
Comparative analysis of methods and tools applicability for product and IPSS development based on Text Mining Techniques
}

\author{
Caio Augusto Nunes Marques, Ivone Penque Matsuno ${ }^{a}$, Roberta Akemi Sinoara ${ }^{a}$, \\ Solange Oliveira Rezende ${ }^{a}$, Henrique Rozenfeld ${ }^{a}$ \\ aniversidade de São Paulo \\ e-mails: caiomarques@usp.br; ivone.matsuno@usp.br; rsinoara@usp.br; solange@icmc.usp.br; roz@sc.usp.br
}

\begin{abstract}
Industrial Product-Service Systems (IPS ${ }^{2}$ ) is an innovative way of doing business potentially capable of answering sustainability challenges. The interest in IPS ${ }^{2}$ has opened several research branches as one concerned on how to properly develop it. Well-known methods and tools have been adapted for IPS ${ }^{2}$ development or new ones created by researches. This knowledge is spread out in publications and in the web and can only be processed by the use of Text Mining (TM) techniques. This paper presents an exploratory research that performs some steps of the TM process with the purpose of identifying and assessing which methods and tools are already applied at practical real cases. With this information, an user can select the most appropriated method or tool for her/his organization. The process assessed the 2009-2014 CIRP IPSS Proceedings and it was possible to start an applicability study of both traditional methods and tools, and those specific for IPS ${ }^{2}$ development. This application provided promising results and insights for future work on this research, e. g.: to perform the next TM process steps; to explore other TM techniques; to create an applicability metric; and to incorporate other sources of documents.
\end{abstract}

Keywords: Product-Service System, Text Mining, methods and tools.

\section{Introduction}

Product-Service System (PSS) is an approach that changes the focus of the business from the development and selling of physical products to a system composed by products and services, which can comply with clients' specific needs (HINZ; BEY; McALOONE, 2013; MANZINI; VEZZOLI, 2003; SHIMOMURA; HARA; ARAI, 2009). Tan (2010) defines PSS as a new approach that integrates activities and competences of an organization and intensifies the relationship between clients and partners in the value chain.

New challenges are associated with the development and commercialization of PSS concerning the definition of new business models, which are essential to successfully implement a PSS (BARQUET et al., 2013; MEIER; BOßLAU, 2012; MONT; TUKKER, 2006; REIM; PARIDA; ÖRTQVIST, 2014; TAN, 2010). As the adoption of PSS oriented business models are yet limited, new methods for PSS development are expected to be proposed (BAINES et al., 2007; MEIER; ROY; SELIGER, 2010; MEIER, 2012; NGUYEN; SCHNÜRMACHER; STARK, 2014; REIM; PARIDA; ÖRTQVIST, 2014). However, some authors believe that the development of PSS is an expansion of product development scope (MANZINI;
VEZZOLI, 2003; TAN, 2010), what would suggest that the traditional methods for product design and/or service design could be used for PSS development.

It seems that in the last years several researches have been carried out to develop design methods and tools but practical application cases have not been reported, i.e. many of them were only theoretical development (MCMAHON, 2012). To Fulea and Brad (2011) this situation is even worst related to the adoption of PSS specific methods and tools by the industry.

The proposals of new methods and tools are constantly growing and the sources of knowledge are spread out in publications and also in the web. Thus there might be an approach to continuously update the information about new methods, tools, practices and cases, in order to corroborate their real world practical application.

To face with these challenges there is an ongoing research project that intends to build an open access portal of knowledge about design practices, methods and tools. The main goal is to open the possibility of a collaborative evaluation of those practices, methods and tools concerning its practical application in real cases by researches, consultants and practitioners, as illustrated in 
Figure 1. Thus a practitioner could decide to use in her/his organization practices, methods and tools already validated.

One potential limitation is the steady creation of new methods and tools whose description can be found in many sources of information, such as publications in journals and web (blogs, news, white papers, etc.). Manual monitoring of which new method or tool is appropriated to a real application for practitioners becomes impossible. This big data can only be analyzed based on Text Mining (TM) techniques. After a method or tool is automatically identified, it can be verified and be inserted in the portal. Afterwards the community can add information, about additional practical applications, descriptions of cases, advantages and under performances, implementations barriers and so on. This represents a possible ongoing evaluation of them (Figure 1).

This paper reports an exploratory study with the purpose of employing the initial steps of a procedure based on
Text Mining techniques to support the identification of PSS design methods and tools which have been already applied in practical real cases. The procedure, proposed in a previous work (MARQUES et al., 2015), is highlighted in the Figure 1 by the textured box. In this work, the first steps of this procedure was applied on the Proceedings the CIRP International Conference on Industrial Product-Service Systems from 2009 to 2014, since it is the leading conference on Product-Service Systems.

The next section presents fundamental references about methods and tools for PSS design. Section 3 brings essential concepts about Text Mining. Section 4 describes the procedure adopted. The application on CIRP IPSS Proceedings is presented and discussed in section 5. The final remarks with the conclusions and description of the next steps of this research are presented in section 6 .

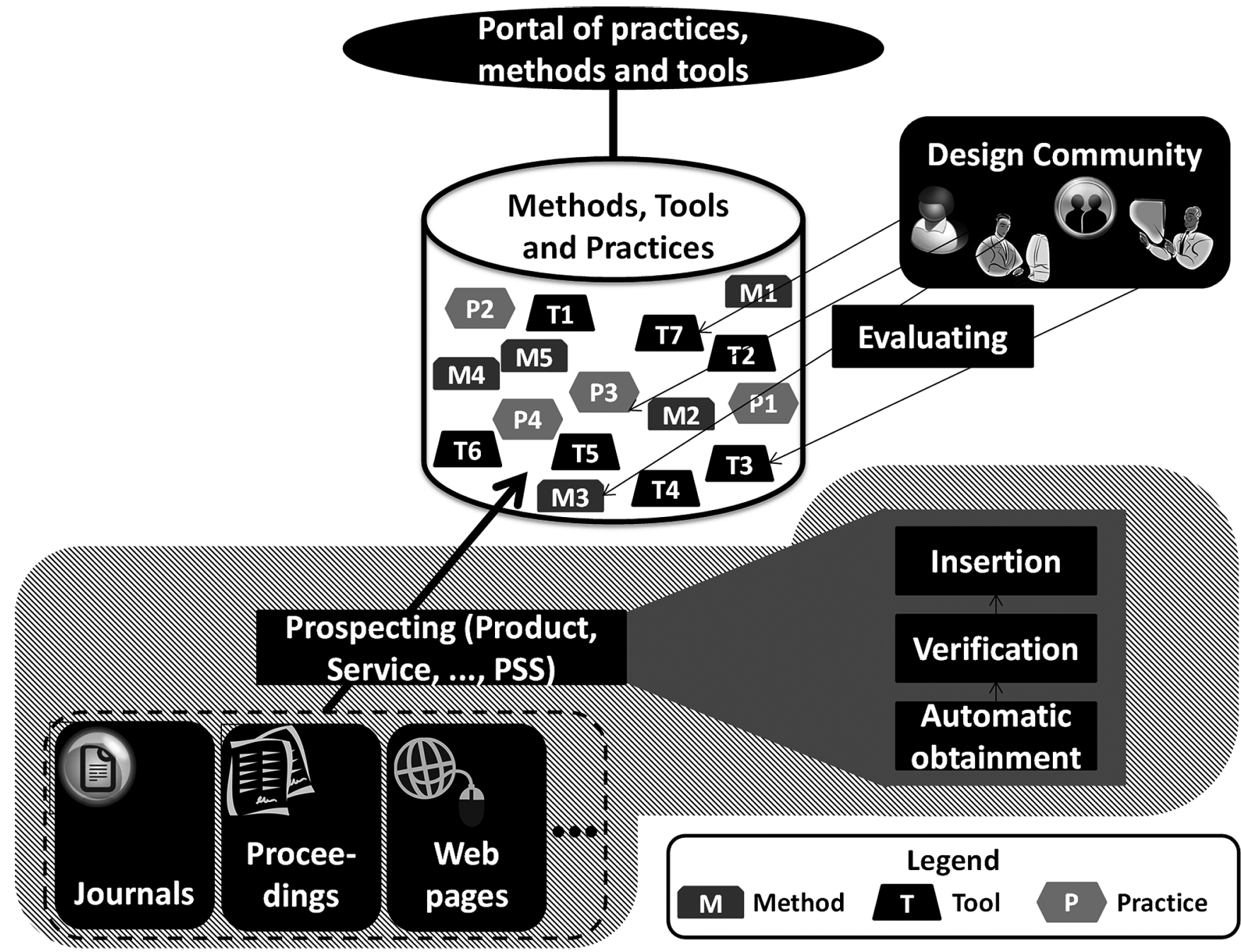

Figure 1. The concept of an open access portal of knowledge about design practices, methods and tools and the scope of this publication highlighted (automatic identification of methods and tools with practical application). 


\section{Methods and tools for PSS development}

The challenge of developing PSS has driven part of the scientific community to put efforts to identify appropriated design methods and tools. Some researchers have adopted the parsimony principle and have been studying if what are already developed to pure products can be successfully used in PSS design, even with adjustments. Morelli (2006), e.g., identified some methods and tools from others disciplines that he judged as being useful in PSS design projects in which he took part.

Cavalieri and Pezzotta (2012) affirm that companies usually adopt approaches based on pure product design, which are rigorously applied at the "tangible" part of the system, but still develop the "intangible" part in an intuitive way. Given the systemic profile of a PSS, adaptations should be made in order to meet the stakeholders needs (BEUREN; FERREIRA; CAUCHICK MIGUEL, 2013). Morelli (2006), Baines et al. (2007) and Hinz, Bey and Mcaloone (2013) agree that there is still a lack of well-developed and standardized methods and tools which may provide the companies with a PSS' implementation guide. Meier, Roy and Seliger (2010), Meier (2012) and Nguyen, Schnürmacher and Stark (2014) stated that companies need new methods and tools at both managerial and engineering levels to be capable of satisfactorily designing Industrial Product-Service Systems (IPS ${ }^{2}$ ). Hinz, Bey and Mcaloone (2013) affirm that there is still a lack of understanding about how a PSS should be designed.

Many authors perceived this demand and have been researching new methods and tools specifically to design PSS: Yang et al. (2009) reviewed some methods and tools; Meier (2012) presents some methods for IPS ${ }^{2}$ planning, concept modeling and design, resulted from the collaborative research project SFB/TR 29; Shimomura and Akasaka (2013) describe how they have been developing new PSS methods and tools; Kimita and Shimomura (2014) argue that some design methods and evaluation tools have been developed specifically for PSS.

Although several efforts have been carried out in order to develop methods and tools appropriated to IPS $^{2}$ that research area still needs systematic knowledge (PEZZOTTA et al., 2011). The majority of PSS' methods and tools are generic and not specific.

In summary, there is a range of methods and tools described in PSS literature, but still there is a lack of critical and in depth evaluation about their relevance (BAINES et al., 2007). The keyword is application. There is already a set of methods and tools derived from product design theory or specifically developed for PSS design, however there is still a need for thorough and rigorous evaluation of their performance in real cases (BAINES et al., 2007; BEUREN; FERREIRA; CAUCHICK MIGUEL, 2013). Baines et al. (2007) argue that the completeness of these methods and tools claims for evidences. Cavalieri and Pezzotta (2012) affirm that there are few utilization reports of these methods and tools in real cases. According to Morelli (2006), new case studies and more detailed applications may help to define a methodological approach to PSSs design.

\section{Text Mining}

A large amount of documents is stored daily in textual format in digital media. As the volume of information generated is greater than the human capacity can process, Text Mining (TM) techniques have become essential for supporting knowledge extraction (AGGARWAL; ZHAI, 2012; GUPTA; LEHAL, 2009). TM process is usually divided into five steps: problem identification, preprocessing, pattern extraction, post-processing and knowledge usage (FELDMAN; SANGER, 2007; REZENDE, 2003). This process is iterative and the internal steps may be executed several times, depending on the post-processing results.

The problem identification step will guide the whole process. In this step the objectives of the TM process are defined and the text collection is identified. In the preprocessing step, the text collection is structured in a format that is proper to knowledge extraction. The goal of the pattern extraction step is to identify patterns in the preprocessed data. There are several tasks that can be performed in this step. Classification, clustering and association rules are examples of those tasks. The knowledge extracted (i.e., the patterns) are evaluated in the post-processing step. If the knowledge matches the objectives of the TM process, it is prepared to the knowledge usage final step. If the knowledge does not match the TM process objectives, the cycle preprocessing-pattern extraction-post-processing is restarted.

This work employs the first steps of a procedure proposed by the authors in a previous work (MARQUES et al., 2015) to identify and evaluate the applicability of methods and tools for designing PSS from a collection of documents. The procedure, described in the next section, proposes the instantiation of TM process in three different moments, in order to support the knowledge extraction about the application of methods and tools for designing Product Service Systems. Each instantiation is performed with a different purpose and therefore, using different techniques. Details are presented in the next section.

\section{Procedure to identify and evaluate the applicability of methods and tools}

The procedure to identify and evaluate the applicability of methods and tools for designing PSS from a collection of documents is illustrated in Figure 2. This is an initial proposal and might be refined as the research progresses. The detail of each step is presented in the following. 


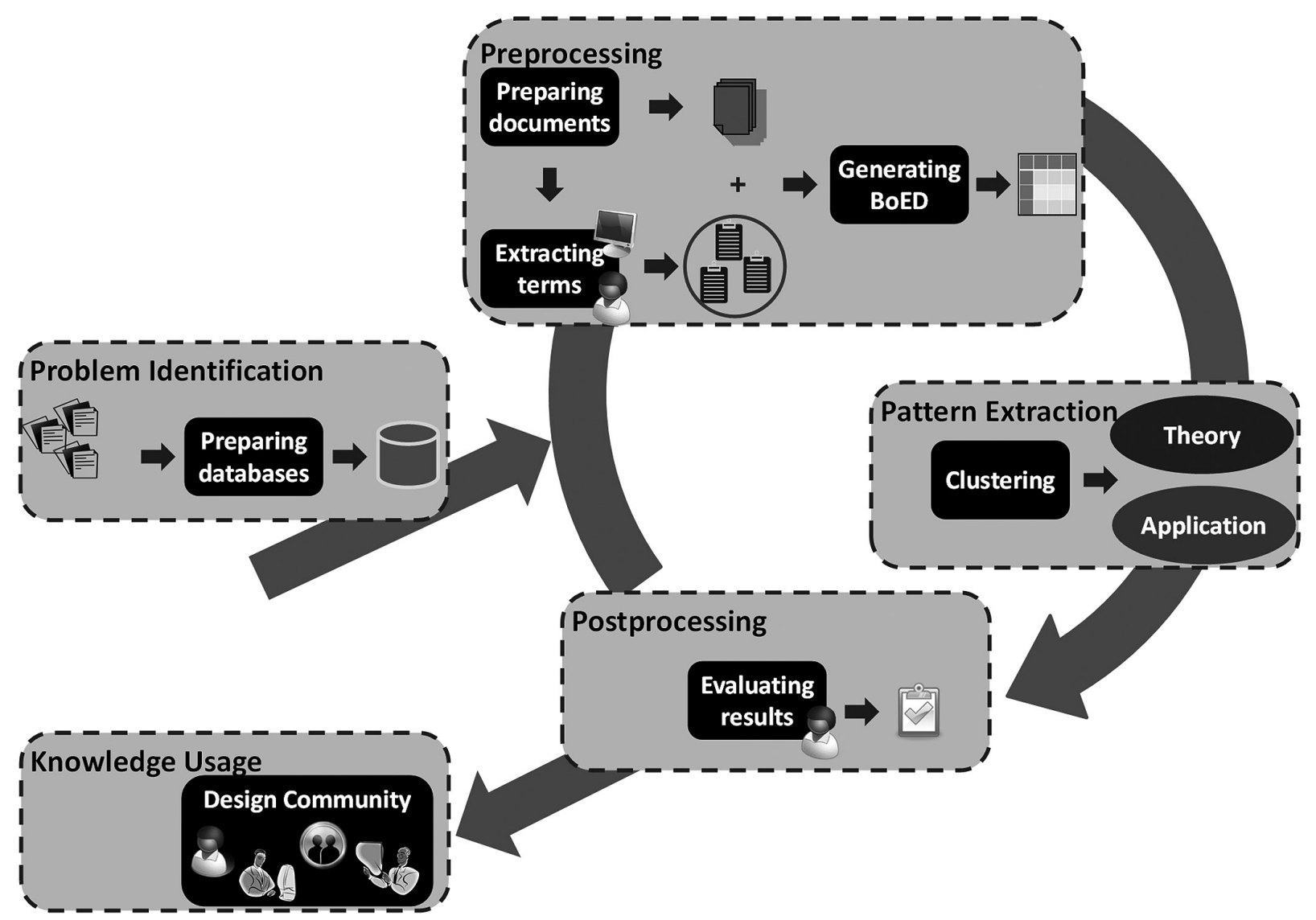

Figure 2. Instantiation of Text Mining process. Adapted from Rezende (2003).

\subsection{Problem identification}

This step consists of preparing the database by selecting a set of documents dealing with methods and tools for PSS design. After defining this text collection, the preprocessing step is started.

\subsection{Preprocessing}

In the preprocessing step, three activities are performed: preparation of documents; extraction of domain terms; and generation of a bag-of-expressions-of-domain (BoED).

\subsubsection{Preparing the documents}

The text collection must be prepared to the next activities. The text collections are normally found in PDF or HTML files. In order to allow the next steps, each document must correspond to a single file in plain text format (TXT files).

\subsubsection{Extracting terms}

The term extraction activity aims to generate three lists of words (or phrases) of the domain: i) a list of names of methods and tools; ii) a list of words that the authors use to indicate that a method or tool has been applied; and iii) a list of words that authors use to present a theoretical work about particular method or tool. This activity can be done manually or with the support of TM techniques.

The manual identification consists of selecting and reading a set of reference articles to generate the three lists. The terms identification supported by TM can be performed using Named Entity Recognition (NER) methods or association rules generation. Those are two additional instantiation of TM process. These techniques can be used with the purpose of automatically extract the terms and domain expressions from the documents and generate a list to be evaluated by the domain expert.

NER involves processing a text to identify and classify the occurrences of words or expressions considered Named Entities (NE) (GRISHMAN; SUNDEHEIM, 1996). NEs include all entities that can be identified by a proper name, such as people, organizations, locations, brands and products, as well as temporal and numeric expressions. In the approach proposed in a previous work (MARQUES et al., 2015), NER is used to extract the names of methods and tools for PSS development process, thus supporting the construction of the first list of terms (list of methods and tools).

The association rule mining was originated in market basket analysis (AGRAWAL; IMIELINSK; SWAMI, 1993), 
with the extraction of rules such as "customers who buy the products $\mathrm{x}_{1}$ and $\mathrm{x}_{2}$ also buy the product $\mathrm{y}$ ". However, the applicability of association rules is not restricted to the analysis of market baskets. In general, an association rule is an implication of the form $A \Rightarrow B$, in which $A$ is the antecedent and $\mathrm{B}$ is the consequent. $\mathrm{A}$ and $\mathrm{B}$ are disjoint subsets of a set of items (or in this particular case, words) $\mathrm{I}=\left\{\mathrm{i}_{1}, \mathrm{i}_{2}, \ldots, \mathrm{i}_{\mathrm{m}}\right\}$ and the association rule is generated from a set of transactions, where a transaction is a subset of $\mathrm{I}$. The association rule $\mathrm{A} \Rightarrow \mathrm{B}$ occurs in the transactions set with confidence conf if in $100 *$ conf $\%$ of the transactions that occurs $\mathrm{A}$ also occurs $\mathrm{B}$. The rule $\mathrm{A} \Rightarrow \mathrm{B}$ has support sup if $100 * \sup \%$ of transactions occurs A and B.

In the proposed approach, the set of items consists of the words found in the text collection and the transactions can be created by two different approaches: i) sentences, i.e., each sentence of the articles form a transaction; or ii) sliding windows, where transactions are extracted by sliding windows in each document (for example, considering a window size of 10 , each transaction is formed considering up to 10 words in sequence). Our proposal suggests using association rules for support the extraction of a set of terms that may indicate the words related to theoretical development or application of a method or tool.

\subsubsection{Generating a Bag of Expressions of the Domain (BoED)}

In the preprocessing step of a TM process, textual collections are usually represented as a bag-of-words (BoW). Bow is a document-term matrix, where each row represents a document, each column represents a word present in the collection of documents and each cell contains a measure of frequency of the word in the document. In this approach, the construction of a bag-of-expressions-of-domain (BoED) is proposed, whose difference from the bag of words is that words are replaced by domain expressions.
A domain expression is formed by terms from the three lists of terms described in section 4.2.2 and it is formally presented below:

- $\mathrm{M}=\left\{\mathrm{m}_{1}\left(\mathrm{~s}_{11}, \cdots, \mathrm{s}_{1 \mathrm{i}}\right), \mathrm{m}_{2}\left(\mathrm{~s}_{21}, \cdots, \mathrm{s}_{2 \mathrm{i}}\right), \cdots, \mathrm{m}_{\mathrm{k}}\left(\mathrm{s}_{\mathrm{k} 1}, \cdots, \mathrm{s}_{\mathrm{ki}}\right)\right\}$, set that contains the name of the selected $\mathrm{k}$ methods or tools for analysis and their respective synonyms $\left(\mathrm{s}_{\mathrm{i}}\right)$

- $\mathrm{A}=\left\{\mathrm{a}_{1}\left(\mathrm{~s}_{11}, \cdots, \mathrm{s}_{1 \mathrm{i}}\right), \mathrm{a}_{2}\left(\mathrm{~s}_{21}, \cdots, \mathrm{s}_{2 \mathrm{i}}\right), \cdots \mathrm{a}_{\mathrm{p}}\left(\mathrm{s}_{\mathrm{p} 1}, \cdots, \mathrm{s}_{\mathrm{pi}}\right)\right\}$, set that contains the $\mathrm{p}$ expressions that indicate the application of a method or tool and their respective synonyms $\left(\mathrm{s}_{\mathrm{i}}\right)$;

- $\mathrm{T}=\left\{\mathrm{t}_{1}\left(\mathrm{~s}_{11}, \cdots, \mathrm{s}_{1 \mathrm{i}}\right), \mathrm{t}_{21}\left(\mathrm{~s}_{21}, \cdots, \mathrm{s}_{2 \mathrm{i}}\right), \cdots, \mathrm{t}_{\mathrm{q}}\left(\mathrm{s}_{\mathrm{q} 1}, \cdots, \mathrm{s}_{\mathrm{qi}}\right)\right\}$, set that contains q expressions that indicate a theoretical development of a method or tool and their respective synonyms $\left(\mathrm{s}_{\mathrm{i}}\right)$.

Each expression of domain is composed by a term of $\mathrm{M}$ matched to a term of A or T. The expressions of domain are searched in each sentence of the documents. The frequency of each expression in each document is calculated and the BoED is built for the text collection. In Figure 3 is shown the BoED for a collection of $\mathrm{n}$ documents represented from expressions generated by $\mathrm{k}$ methods, $\mathrm{p}$ application expressions and q expressions of theoretical development.

\subsection{Pattern extraction}

In patter extraction step, clustering methods are usually used when the objective of TM process is to organize the collection of documents and labelled documents are not available. Text clustering aims to organize a collection of documents into clusters (groups), so that documents of the same cluster are highly similar and dissimilar to documents from other clusters. The proposal is to use the BoED as input for clustering algorithms to organize the collection of articles into two clusters: documents relating to applications of methods/tools and documents relating to theoretical development of methods/tools.

\begin{tabular}{|l|c|c|c|c|c|c|c|c|c|c|c|c|c|c|}
\hline & $m_{1}+a_{1}$ & $\ldots$ & $m_{1}+a_{p}$ & $\ldots$ & $m_{k}+a_{1}$ & $\ldots$ & $m_{k}+a_{p}$ & $m_{1}+t_{1}$ & $\ldots$ & $m_{1}+t_{q}$ & $\ldots$ & $m_{k}+t_{1}$ & $\ldots$ & $m_{k}+t_{q}$ \\
\hline$d_{1}$ & & & & & & & & & & & & & & \\
\hline$d_{2}$ & & & & & & & & & & & & & & \\
\hline$d_{3}$ & & & & & & & & & & & & & & \\
\hline$\cdot$ & $\cdot$ & & $\cdot$ & & $\cdot$ & & $\cdot$ & $\cdot$ & & $\cdot$ & & $\cdot$ & & $\cdot$ \\
$\cdot$ & $\cdot$ & & $\cdot$ & & $\cdot$ & & $\cdot$ & $\cdot$ & & $\cdot$ & & $\cdot$ & \\
$\cdot$ & $\cdot$ & & $\cdot$ & & $\cdot$ & & $\cdot$ & $\cdot$ & & $\cdot$ & & $\cdot$ & & $\cdot$ \\
\hline$d_{n}$ & & & & & & & & & & & & & & \\
\hline
\end{tabular}

Figure 3. Bag of Expressions of the Domain (BoED) Schema. 


\subsection{Post-processing}

The post-processing step refers to the evaluation of the knowledge (patterns) extracted in the previous step. That analysis will determine whether previous steps must be repeated or not. The TM internal cycle will end when the post-processing activities concludes that the TM goal (stated in the problem identification step) was achieved.

\subsection{Knowledge usage}

This last step comprises the use of the knowledge acquired by the TM process. In this case, the knowledge of interest is the automatically identified methods and tools as well as their applicability mentioned in the scientific publications considered. This knowledge will be incorporated to the Portal of Knowledge in an ongoing process as described in section 1 and will be available to the design community.

\section{Application in Industrial Product-Service System papers}

The initial steps (problem identification and preprocessing) of the procedure described at the previous section were performed at the Proceedings of CIRP International Conference on Industrial Product-Service Systems from 2009 to 2014, whose number of papers by year is expressed in Table 1. The purpose was to execute an exploratory assessment of the relation applicability/theoretical development of the papers presented at the referred Proceedings.

Initially, each paper was converted from PDF to TXT format. The second activity was the building of three lists of terms: methods and tools; application terms; theoretical development terms. These three lists were constructed by employing two approaches: manual and supported by TM.

The manual identification followed the following flow: reading of the papers' abstracts; identifying if the paper is about PSS' methods and/or tools; identify methods and tools, terms used to indicate application and terms used to express theoretical development; search for variations of

Table 1. Number of papers published int he Proceedings of CIRP International Conference on IPSS from 2009 to 2014.

\begin{tabular}{|c|c|}
\hline Year & Papers \\
\hline 2009 & 51 \\
\hline 2010 & 69 \\
\hline 2011 & 60 \\
\hline 2012 & 89 \\
\hline 2013 & 54 \\
\hline 2014 & 65 \\
\hline Total & 388 \\
\hline
\end{tabular}

the terms, such as synonymous and verbal tenses; building of three lists.

The list of methods and tools is composed by terms as Quality Function Deployment (QFD) and System Map and they synonymous, as presented at Annex 1 . The second list has terms as apply, use, real case and its variations, adopted to indicate application of a method or tool. The last list has the terms used to express theoretical development and comprises words such as propose, present and describe. The complete list of terms used to express application or theoretical development is presented at Annex 2.

In order to assess the possibility of automatic identification of IPS ${ }^{2}$ methods and tools, NER was employed by using OpenCalais Service (www.opencalais.com). This tool uses natural language processing and other methods of machine learning to find named entities, facts and events in documents. Entities recognized as Industry Term and Technology were evaluated.

With this approach, only 10 methods and tools were identified in a universe of 81 listed manually. This low number of recognitions might be due the domain specificity, i. e., generally the papers brings innovative items, so OpenCalais service doesn't has those methods and tools in its base.

In order to find the possible words that represent terms that may indicate the theoretical or practical use of a method or tool, association rules were generated with Apriori algorithm (AGRAWAL, IMIELINSK and SWAMI, 1993). The text collection was processed to generated transactions from sentences and sliding windows. Only the transactions that contained the words "method", "methods", "tool" or "tools" were used to generate the association rules. Association rules whose consequent was one of those words were selected for review. It was tried to identify words representing terms of application or theoretical development in the antecedent of those rules.

It was observed that the rules have adequate list of issues addressed in papers, identifying relations as: $\{$ process $\} \Rightarrow\{$ tools $\},\{$ service $\} \Rightarrow\{$ method $\}$, \{product, service $\} \Rightarrow\{$ tools $\},\{$ pss $\} \Rightarrow\{$ method $\}$ and others. The only rule identified indicating theoretical use was \{proposed $\Rightarrow$ \{method $\}$.

After the term extraction, a BoED was built. As were found more methods, tools and terms used to express both application and theoretical development in a greater volume via manual identification than by using TM, the decision was using the manually constructed lists.

To illustrate the results, a brief analysis of the generated $\mathrm{BoED}$, is presented in the following. Table 2 presents a summarization of the BoED generated considering only Quality Function Deployment (QFD), Technology Roadmap (TRM), Failure Mode and Effects Analysis (FMEA), Service Blueprint and PSS Layer Method. 
Table 2. Summarization of BoED, related to QFD, TRM, FMEA, Service Blueprint and PSS Layer Method.

\begin{tabular}{|c|c|c|c|c|c|c|}
\hline \multirow[b]{2}{*}{ Method } & \multicolumn{2}{|c|}{ Distinct Expressions } & \multicolumn{2}{|c|}{ Domain Expressions Frequency } & \multicolumn{2}{|c|}{ Documents with domain expressions } \\
\hline & $\begin{array}{c}\text { Application } \\
\text { Terms }\end{array}$ & Theory Terms & $\begin{array}{c}\text { Application } \\
\text { Terms }\end{array}$ & Theory Terms & $\begin{array}{c}\text { Application } \\
\text { Terms }\end{array}$ & Theory Terms \\
\hline QFD & 4 & 5 & 39 & 22 & 16 & 12 \\
\hline FMEA & 5 & 1 & 11 & 5 & 7 & 5 \\
\hline TRM & 5 & 5 & 17 & 21 & 8 & 6 \\
\hline Service Blueprint & 6 & 7 & 67 & 70 & 18 & 20 \\
\hline PSS Layer Method & 7 & 6 & 40 & 23 & 18 & 7 \\
\hline
\end{tabular}

Table 2 exemplifies the type of information that can be extracted from BoED. For example, to QFD, four expressions that indicate the application of this method and 5 that indicate a theoretical development were found at the CIRP IPSS Proceedings. The frequency of the domain expressions which indicate application being bigger than the theoretical development one may mean that QFD is treated more in a practical than in a theoretical perspective. A similar interpretation may be done for the number of documents with expressions which indicate application and expressions which indicate theoretical development of QFD in a PSS perspective.

Adopting the same argument, FMEA has more practical studies than theoretical concerning to PSS development. Otherwise, based on the frequency of the domain expressions, TRM is a method with less application reports than theoretical development ones.

In case of Service Blueprint, were found more domain expressions which indicate more theoretical development than application. This should suggest that Service Blueprint is more frequently approached by researchers in theoretical than practical situations.

The results for PSS Layer Method are noteworthy because, despite being a method created on the PSS area, it were found more application expressions than theoretical development ones.

QFD and FMEA have in common its origins out of PSS theory. They are well-known methods from traditional product development which have been studied in PSS context. This may explain why these methods have more practical applications reports in the PSS context than those methods created specifically to PSS development.

\section{Conclusions}

This exploratory research applied the initial steps of a procedure based on Text Mining techniques to support the identification of PSS design methods and tools which have been already applied in practical real cases. From the BoED generated from the CIRP IPSS Proceedings was already possible to make an initial analysis of the applicability of some PSS methods. A complete analysis can be done with the execution of the pattern extraction and post-processing steps of the procedure. This will be the next step of this research. Clustering methods will be applied in order to distinguish documents which reports practical application of a PSS method or tool from those which have a theoretical perspective. Some approaches for this task are: i) use the BoED as privileged information, being a complement to the textual representation based on the traditional BoW (MARCACINI; REZENDE, 2013; SINOARA et al., 2014); ii) explore the use of other text representation techniques, such as the bag-of-related-words (ROSSI; REZENDE, 2011); iii) employ the interactive textual feature selection (CORRÊA et al., 2015); iv) apply methods to identify descriptors for the clusters found, such as the method proposed by Santos, Rezende and Oliveira (2014).

Related to the automatic identification of methods and terms that may indicate the words related to theoretical development or application of a method or tool, the procedure has some limitations, however the results indicate its feasibility. Few methods and tools were found using a generic NER tool. Thus, there is a need to adapt the NER technique to perform better in this domain. It is understood that it is also possible to improve the use of Association Rules technique in order to capture more significant rules.

It was already possible to recognize some methods and tools in an automatic manner, to identify some relations and to verify, yet inconclusively, the applicability of some methods and tools for PSS design. As an ongoing research, there are still open issues. It is important to avoid cases as "QFD applies matrixes..." which would be captured as an application expression instead being a theoretical development one. Thus, a deeper investigation of the techniques we have adopted is being performed. Additional tests, as well as improvements, are being made in order to turn the initial proposal a more robust procedure to achieve better results.

Accordingly to the Portal of Knowledge context approached in the introduction of this paper, other sources of information about PSS methods, tools and practices will be analyzed in order to permit a more robust assessment. A metric must be created to make possible the comparison between methods and tools based on their application to real cases. 


\section{Acknowledgements}

The authors would like to thank Capes (Higher Education Personnel Training Coordination) and grant \#2014/08996-0 and \#2013/14757-6, São Paulo Research Foundation (FAPESP) for financial support.

\section{References}

AGGARWAL, C. C.; ZHAI, C. Mining text data. London: Springer, 2012.

AGRAWAL, R.; IMIELINSK, T.; SWAMI, A. N. Mining association rules between sets of items in large databases. In: ACM SIGMOD INTERNATIONAL CONFERENCE ON MANAGEMENT OF DATA, 19., 1993, Washington. Proceedings... New York: ACM, 1993. p. 207-216.

BAINES, T. S. et al. State-of-the-art in product-service systems. Proceedings of the Institution of Mechanical Engineers. Part B, Journal of Engineering Manufacture, v. 221 , n. 10, p. 1543-1552, 2007. http://dx.doi. org/10.1243/09544054JEM858.

BARQUET, A. P. B. et al. Employing the business model concept to support the adoption of product-service systems (PSS). Industrial Marketing Management, v. 42, n. 5, p. 693-704, 2013. http://dx.doi.org/10.1016/j. indmarman.2013.05.003.

BEUREN, F. H.; FERREIRA, M. G. G.; CAUCHICK MIGUEL, P. A. Product-service systems: a literature review on integrated products and services. Journal of Cleaner Production, v. 47, p. 222-231, 2013. http://dx.doi. org/10.1016/j.jclepro.2012.12.028.

CAVALIERI, S.; PEZZOTTA, G. Product-service systems engineering: state of the art and research challenges. Computers in Industry, v. 63, n. 4, p. 278-288, 2012. http:// dx.doi.org/10.1016/j.compind.2012.02.006.

CORREAA, G. N. et al. Interactive textual feature selection for consensus clustering. Pattern Recognition Letters, v. 52, p. 25-31, 2015. http://dx.doi.org/10.1016/j.patrec.2014.09.008.

FELDMAN, R.; SANGER, J. The text mining handbook: advanced approaches in analyzing unstructured data. Cambridge: Cambridge University Press, 2007.

FULEA, M.; BRAD, S. Ontology-based approach for supporting creativity in a pss design methodology. In: CIRP INDUSTRIAL PRODUCT-SERVICE SYSTEMS CONFERENCE, 3., 2011, Braunschweig. Proceedings... Braunschweig: Springer Berlin Heidelberg, 2011. p. 75-80.

GRISHMAN, R.; SUNDEHEIM, B. Message understanding conference-6: a brief history. In: INTERNATIONAL CONFERENCE ON COMPUTATIONAL LINGUISTICS, 16., 1996, Copenhagen. Proceedings... Copenhagen: Center for Sprogteknologi, 1996. v. 1. p. 466-471.
GUPTA, V.; LEHAL, G. S. A survey of text mining techniques and applications. Journal of Emerging Technologies in Web Intelligence, v. 1, n. 1, p. 60-76, 2009. http://dx.doi. org/10.4304/jetwi.1.1.60-76.

HINZ, H. N.; BEY, N.; MCALOONE, T. C. Timing and targeting of pss methods and tools: an empirical study amongst academic contributors. In: CIRP INDUSTRIAL PRODUCT-SERVICE SYSTEMS CONFERENCE, 5., 2013, Bochum. Proceedings... Bochum: Springer Berlin Heidelberg, 2013.

KIMITA, K.; SHIMOMURA, Y. Development of the design guideline for Product-Service Systems In: CIRP INDUSTRIAL PRODUCT-SERVICE SYSTEMS CONFERENCE, 6., 2014, Windsor. Proceedings... Windsor: Springer Berlin Heidelberg, 2014.

MANZINI, E.; VEZZOLI, C. A strategic design approach to develop sustainable product service systems: examples taken from the "environmentally friendly innovation" Italian prize. Journal of Cleaner Production, v. 11, n. 8, p. 851-857, 2003. http://dx.doi.org/10.1016/S09596526(02)00153-1.

MARCACINI, R. M.; REZENDE, S. O. Incremental hierarchical text clustering with privileged information. In: ACM SYMPOSIUM ON DOCUMENT ENGINEERING, 13., 2013, Florence. Proceedings... New YorK: ACM, 2013. p. 231-232.

MARQUES, C. A. N. et al. An exploratory study to evaluate the practical application of PSS methods and tools based on text mining. In: INTERNATIONAL CONFERENCE OF ENGINEERING DESIGN-ICED15, 20., 2015, Milan. Proceedings... Milan: ICED, 2015.

MCMAHON, C. A. Reflections on diversity in design. Journal of Engineering Design, v. 23, n. 8, p. 563-576, 2012.

MEIER, H. Planning and development of Industrial ProductService Systems. In: CIRP INDUSTRIAL PRODUCTSERVICE SYSTEMS CONFERENCE, 4., 2012, Tokyo. Proceedings... Berlin: Springer, 2012.

MEIER, H.; BOSSLAU, M. Design and engineering of dynamic business models for Industrial Product-Service Systems. In: CIRP INDUSTRIAL PRODUCT-SERVICE SYSTEMS CONFERENCE, 4., 2012, Tokyo. Proceedings... Berlin: Springer, 2012

MEIER, H.; ROY, R.; SELIGER, G. Industrial ProductService Systems-IPS2. CIRP Annals - Manufacturing Technology, v. 59, n. 2, p. 607-627, 2010.

MONT, O.; TUKKER, A. Product-Service Systems: reviewing achievements and refining the research agenda. Journal of Cleaner Production, v. 14, n. 17, p. 1451-1454, 2006. http://dx.doi.org/10.1016/j.jclepro.2006.01.017. 
MORELLI, N. Developing new product service systems (PSS): methodologies and operational tools. Journal of Cleaner Production, v. 14, n. 17, p. 1495-1501, 2006. http://dx.doi. org/10.1016/j.jclepro.2006.01.023.

NGUYEN, H. N.; SCHNÜRMACHER, C.; STARK, R. Research on how to introduce the PSS Engineering into industry. In: CIRP INDUSTRIAL PRODUCTSERVICE SYSTEMS CONFERENCE, 6., 2014, Windsor. Proceedings... Windsor: Springer Berlin Heidelberg, 2014.

PEZZOTTA, G. et al. Enhancement in Industrial PSS design based on TRIZ: a case study. In: CIRP INDUSTRIAL PRODUCT-SERVICE SYSTEMS CONFERENCE, 3., 2011, Braunschweig. Proceedings... Braunschweig: Springer Berlin Heidelberg, 2011.

REIM, W.; PARIDA, V.; ÖRTQVIST, D. Product-Service Systems (PSS) business models and tactics - a systematic literature review. Journal of Cleaner Production, v. 97, p. 61-75, 2014.

REZENDE, S. O. Sistemas inteligentes: fundamentos e aplicações. Barueri: Manole, 2003.

ROSSI, R. G.; REZENDE, S. O. Building a topic hierarchy using the bag-of-related-words representation. In: ACM SYMPOSIUM ON DOCUMENT ENGINEERING, 11., 2011, Mountain View. Proceedings... New York: ACM, 2011. p. 195-204.
SANTOS, F. F.; REZENDE, S. O.; OLIVEIRA, V. Identificando o assunto dos documentos em coleções textuais utilizando termos compostos. In: ENCONTRO NACIONAL DE INTELIGÊNCIA ARTIFICIAL E COMPUTACIONAL, 2014, São Carlos. Anais... São Carlos: SBC, 2014. p.550-557.

SHIMOMURA, Y.; AKASAKA, F. Toward ProductService System Engineering: new system engineering for PSS Utilization. In: CIRP INDUSTRIAL PRODUCTSERVICE SYSTEMS CONFERENCE, 5., 2013, Bochum. Proceedings... Bochum: Springer Berlin Heidelberg, 2013.

SHIMOMURA, Y.; HARA, T.; ARAI, T. A unified representation scheme for effective PSS development. CIRP Annals - Manufacturing Technology, v. 58, n. 1, p. 379-382, 2009.

SINOARA, R. A. et al. Named entities as privileged information for hierarchical text clustering. In: INTERNATIONAL DATABASE ENGINEERING \& APPLICATIONS SYMPOSIUM - IDEAS14, 18., 2014, Porto. Proceedings... New York: ACM, 2014, p. 57-66.

TAN, A. R. Service-oriented product development strategies. Lyngby: Technical University of Denmark, 2010.

YANG, X. et al. A practical methodology for realizing product service systems for consumer products. Computers \& Industrial Engineering, v. 56, n. 1, p. 224-235, 2009. http:// dx.doi.org/10.1016/j.cie.2008.05.008. 
Annex 1. List of methods and tools manually identified at the Proceedings of CIRP International Conference on IPSS from 2009 to 2014 .

$$
\text { Method/Tool }
$$

function tree analysis; advanced sequential incident method; qualitative interdependence analysis; pairwise comparison; affinity method; transfer graphs; process modelling method;

service blueprint; failure mode and effects analysis (fmea); concurrent engineering; computer aided design (cad); computer aided engineering (cae); computer aided manufacturing (cam); theory of inventive problem solving (triz); value analysis; service map; quality function deployment (qfd); voice of customer voice of the customer (voc); affordability capability audit tool; analytic hierarchy process (ahp); cost-benefit analysis (cba); sensitivy cost-benefit analysis (scba); life cycle assessment (lca); roadmap (technology roadmapping) (trm); strategic life cycle management matrix (slcm); life cycle costing (lcc); strength weaknesses opportunities and threats (strength weaknesses opportunities threats) (swot); conjoint analysis;

pss concept generation support system (psscgsm); computer numerical controlled machine (cnc machine); finite element method (fem); computational fluid dynamics method (cfd); product-service systems evaluation (psse); persona / scenario analysis; value analysis template (value analysis template for b2b service design); integrated service evaluation framework (isef); importance analysis method; s-a function; stn simulation; design matrix; abduction-based creative design; conflict detection; group decision making; resource allocation; service fmea; service information blueprint; extended service blueprint; liIghtweight value visualizator (livery); function analysis; causal-loop diagram (cld); conceptual service blueprint; pss layer method (ips2 layer method); pss-cad; elviz; system layer analysis map; pss characteristic strategies; su-field analysis method; som-based business chance finder; view model; function embodiment knowledge base; importance analysis; scene transition nets simulation; qualitative service simulator; cost analysis; ps system simulator; scenario planning; design structure matrix (dsm); pss propoasal configuration tool; activity cycle model; promethee; self-organizing method (som); business-process and goal-oriented requirements analysis; computer-aided service design (casd); service engineering methodology (seem); ips2 performance measurement method; pi toolset; intellectual capital statement (ics); system map; actor's map; pcp triangle

Annex 2. List of terms used to express application and terms used to express theoretical development of methods and tools manually identified at the Proceedings of CIRP International Conference on IPSS from 2009 to 2014.

\begin{tabular}{|l|l|}
\hline \multicolumn{1}{|c|}{ Application terms } & Theoretical Development terms \\
\hline apply, applies, applying, applied, application; employ, employs, & $\begin{array}{l}\text { propose, proposes, proposing, proposed; introduce, introduces, introducing, } \\
\text { employing, employed; perform, performs, performing, } \\
\text { performed; conduct, conducts, conducting, conducted; use, } \\
\text { introduced; develop, develops, developing, developed; discuss, discusses, } \\
\text { discussing, discussed; present, presents, presenting, presented; describe, } \\
\text { uses, using, used; validate, validates, validating, validated; real } \\
\text { case, real case study, empirical study, case study, case studies, } \\
\text { describes, describing, described; aim, aims, aiming, aimed }\end{array}$ \\
\hline
\end{tabular}

